\begin{tabular}{llll} 
Al-Rafidain Engineering & Vol.15 & No.2 & 2007 \\
\hline
\end{tabular}

التغاير النوعي للمياه الخام في نهر دجلة وآثار ها على اداء وحدات محطة تصفية مياه اسالة السلامية وائة

حلا حكمت ناظم

معاون

$$
\text { ليليان يعقوب متي }
$$

مدرس مساعد

مهندس

مركز بحوث البيئة والسيطرة على التلوث - جامعة الموصل

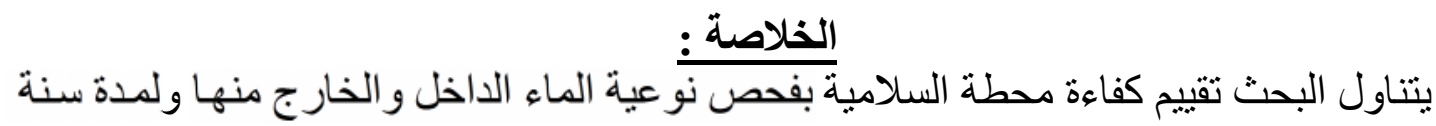

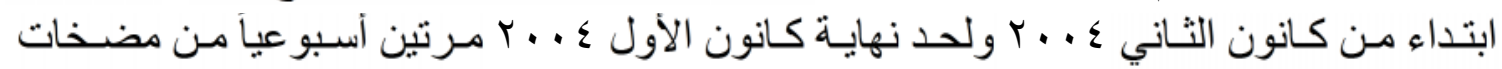

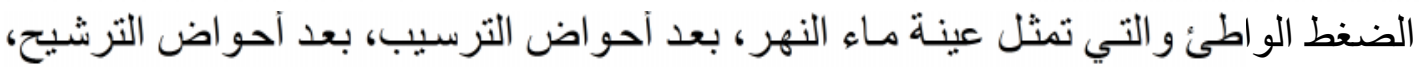

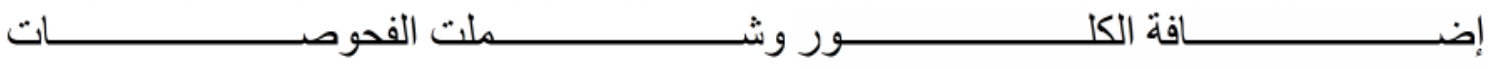

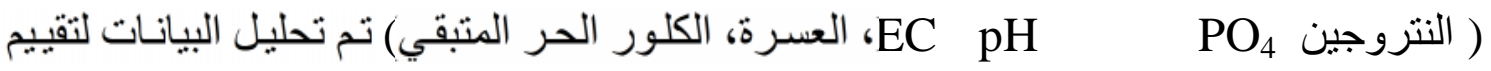

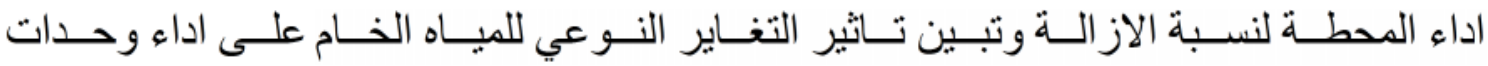

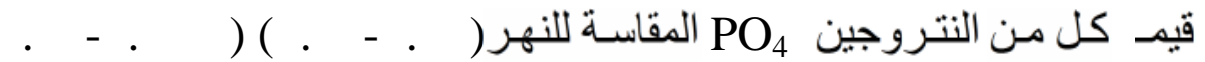

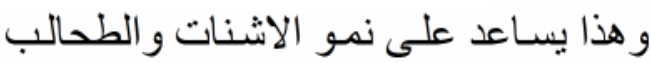

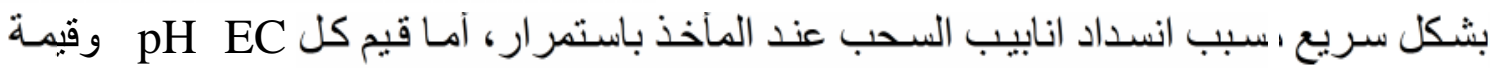

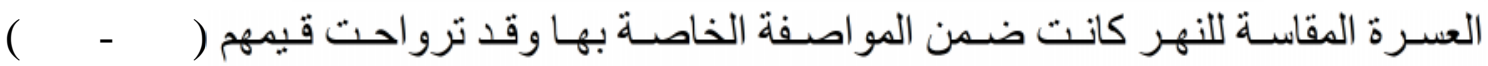

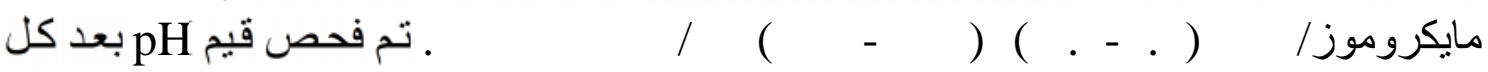
مرحلة من مر احل المعالجة وتبين انها تقل نتيجة إضافة كل من الثب و الكلور حيث وصلت قيمتهـ

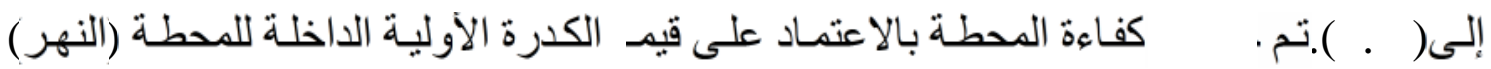

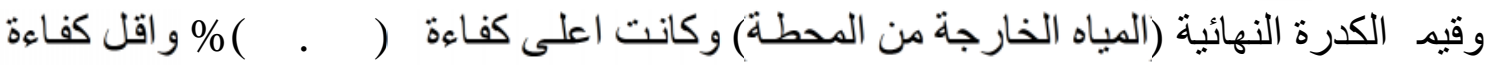

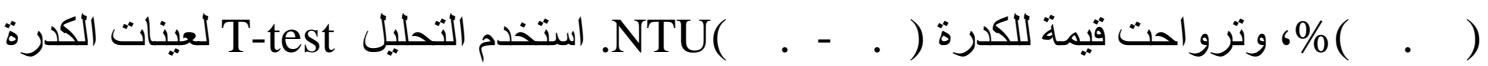

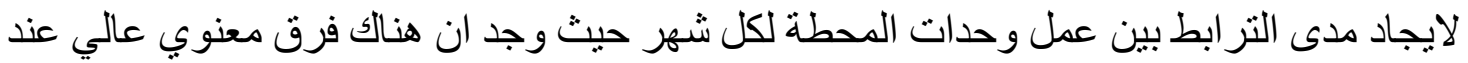

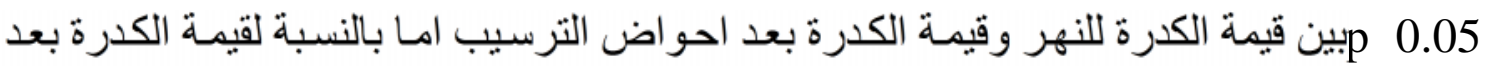
الترسيب وبعد احواض الترشيح فكان الفرق اقل لبعض الأشهر.

\title{
Quality Variation of Tigris River and Effect on the Performance of Water Treatment Units at Al-Salamia Plant \\ Lilian Yaqup Matti \\ Hala Hikmat Nadhim
}

Assistant lecturer
Assistant

Engineer 
Environment and Pollution Control Research Center

\begin{abstract}
This paper focuses on the evaluation of Al-Salamia water supply treatment plant was undertaken for the influent and effluent characteristics twice a week for the period from January 2004 till the end of December 2004 from low lift pump which represents river water sample; after sedimentation tanks; after filtration tanks and after adding chlorine, Physical and chemical measurements (nitrogen, $\mathrm{PO}_{4}$, turbidity, $\mathrm{pH}, \mathrm{Ec}$, Hardness and residual chlorine) were analyzed data to assess the performance of plant and the efficiency removal of turbidity. Nutrients (nitrogen, $\mathrm{PO}_{4}$ ) range between( . - . ) ( . - . ) $\mathrm{mg} / \mathrm{l}$ respectively, which support the algae growth and led to the blocking in intake. Ec, $\mathrm{pH}$ and hardness values are found to be $(440-854) \mathrm{um} / \mathrm{cm}^{2},(7.7-8.6)$ and (185303) $\mathrm{mg} / \mathrm{l}$ respectively. $\mathrm{pH}$ values decrease after adding alum and chlorine

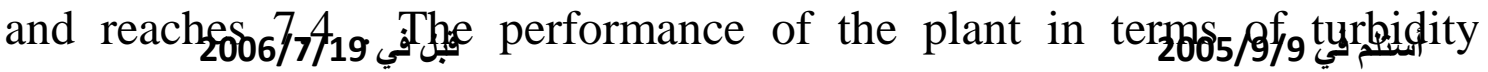
removal ranges from $60.58 \%$ to . \% when effluent turbidity ranges from (2.9 to 8.2) NTU. Paired T-test was used to attain the main objective of this study regarding the turbidity removal efficiency of each units .

المقدمة

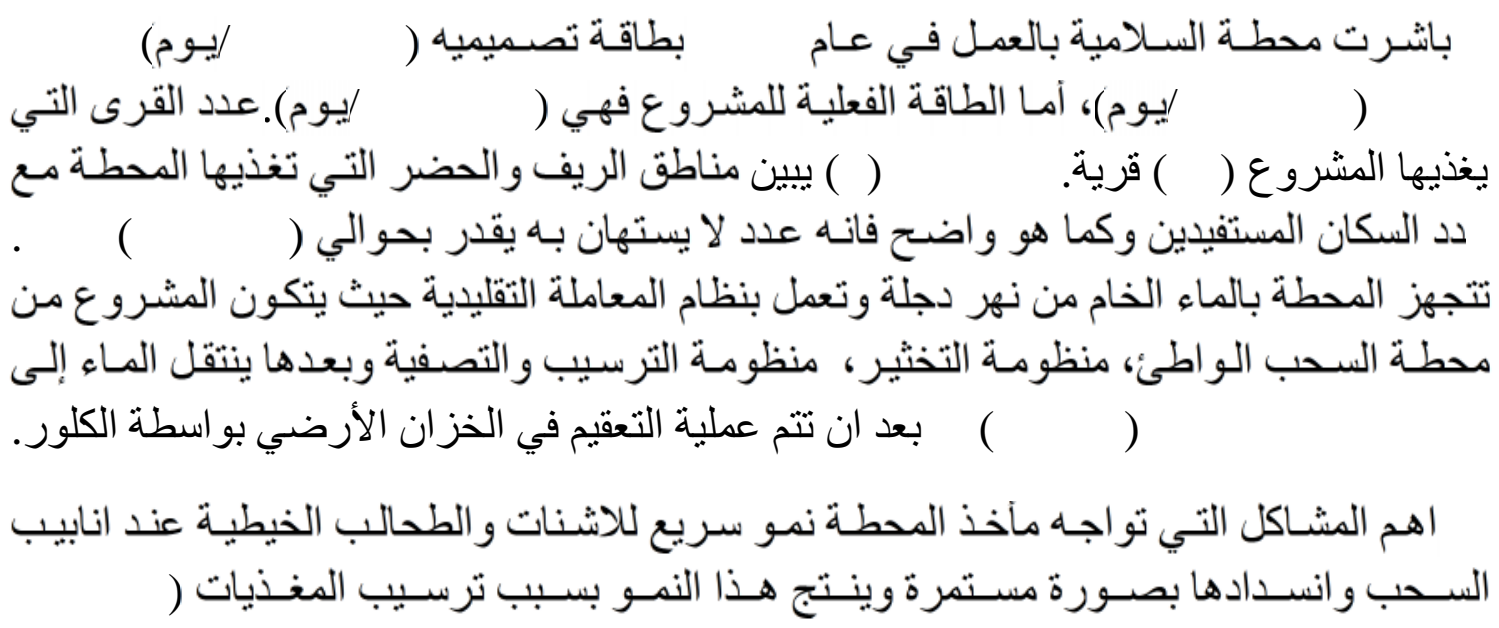
و النتروجين) لناتجة من فعاليات الانسان او بشكل طبيعي لا بمكن السيطرة عليه من المنطقة اعلى

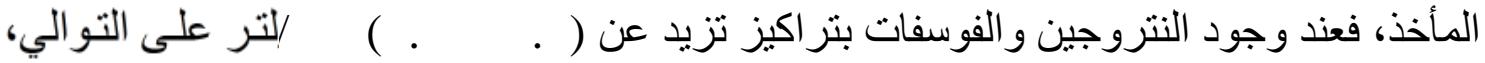

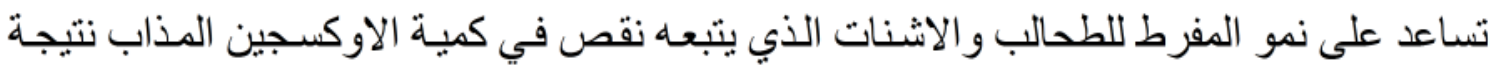


استهلاكه في عمليات تحلل هذه الطحالب من قبل البكتريـا مما يؤثر بشكل عام على نوعية المياه

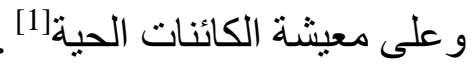

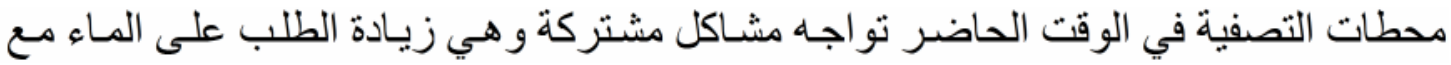

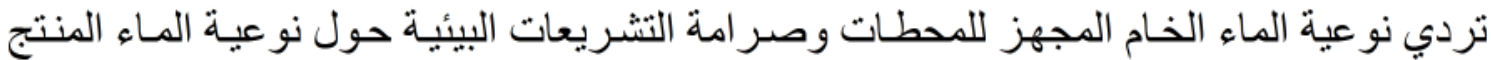

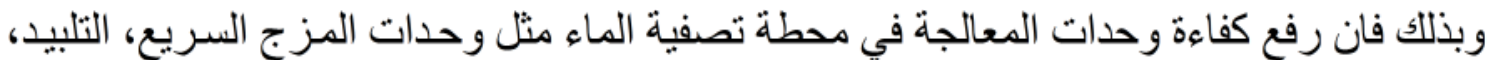
الترسيب و الترشيح سوف يساعد على تحسين في نو عية الماء المنتج فضلاً عن تقليل الكلفة وزيادة التيادة

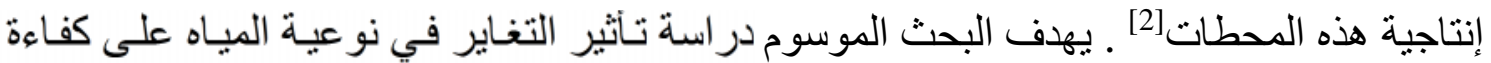

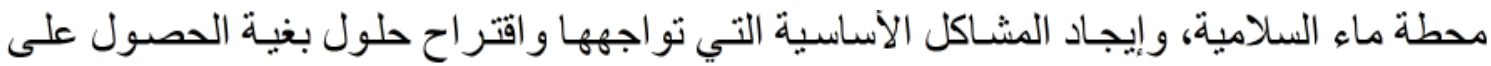
نو عية وكمية جيده للماء المنتج.

الار اسات السابقة

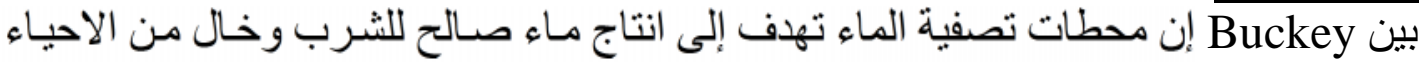

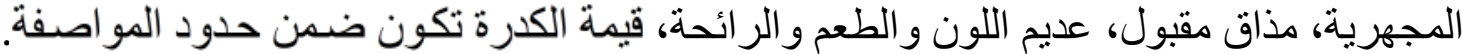
وقد ذكرت العديد من الإجر اءات التي تساعد على تحقيق الاهداف اعلاه ولاه ومنها قياس تركيز الكلور

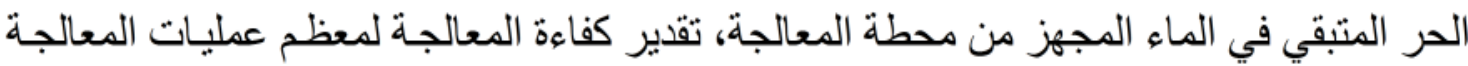
عن طريق معرفة مستوى الكدرة المتبقية بعد كل من وحدتي الترسيب و الترشيح وقياس قيم الرقات الترقي

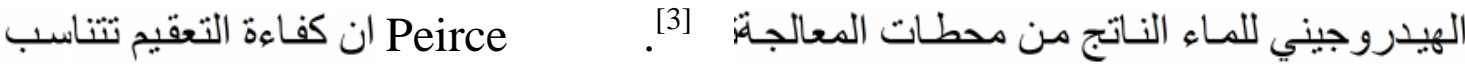

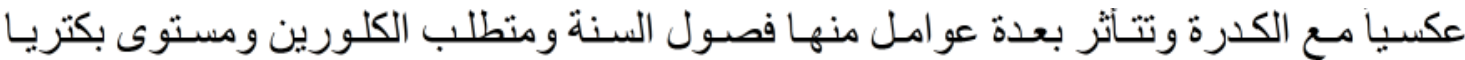

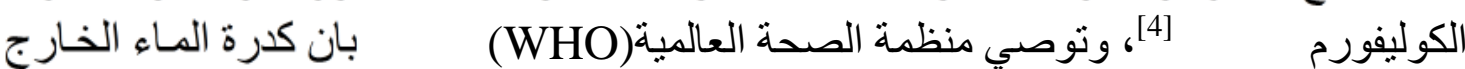

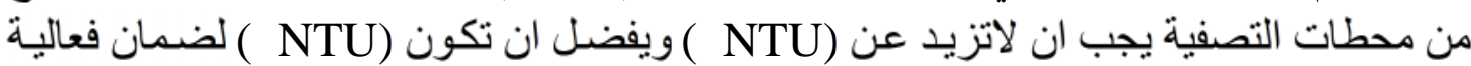

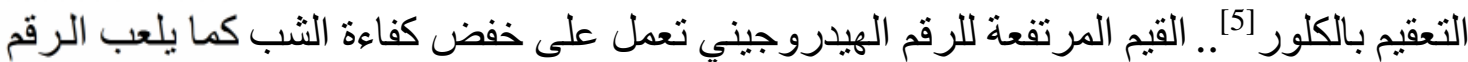

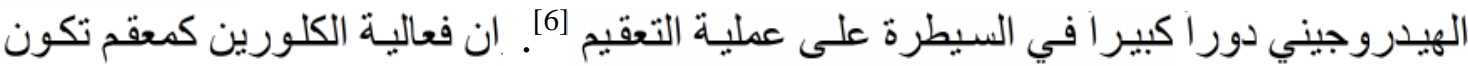

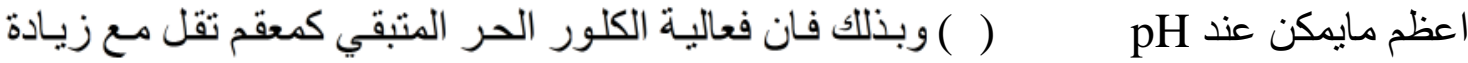

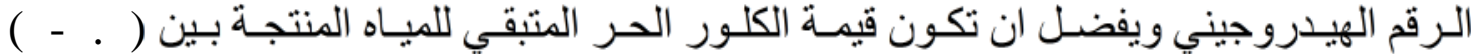

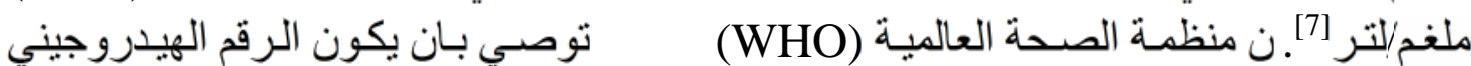

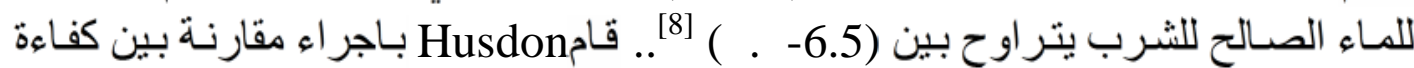

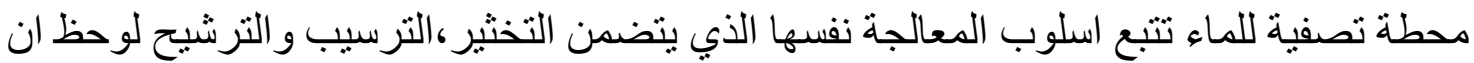

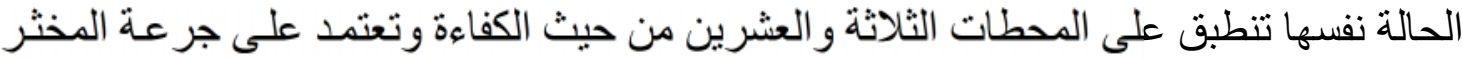

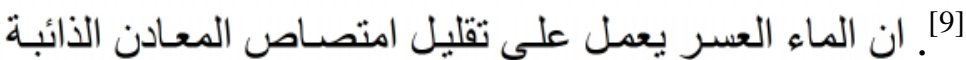

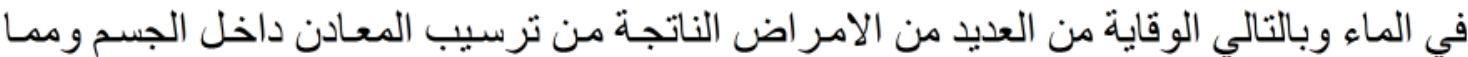
يتعلق بالاضر ار الاقتصادية للماء العسر [10]. 


\section{وصف لمشروع السلامية والمناطق التي يغذيها}

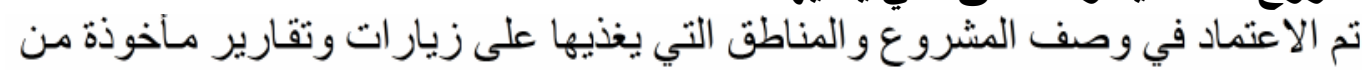
موقع المشروع، ويتكون المشروع من الوحدات الاتية:

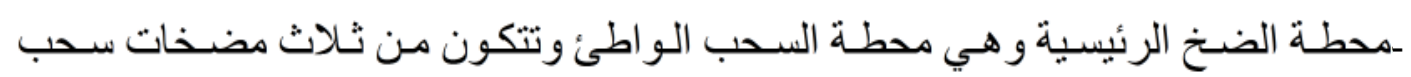

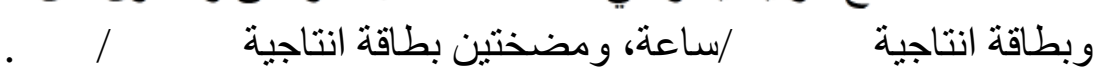

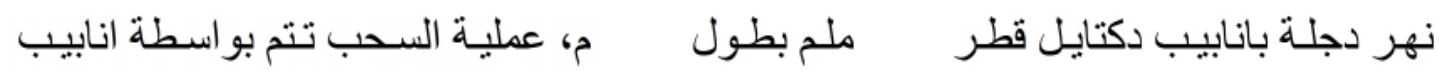

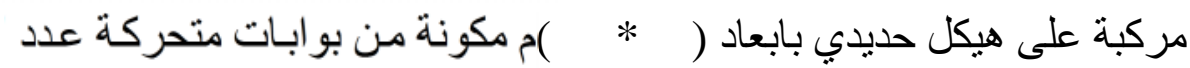

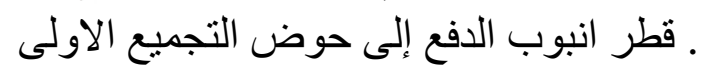

ـ منظومة الترسيب و التصفية، تتكون من ثلاثة أحو اض ترسيب دائريـة الثكل بقطر

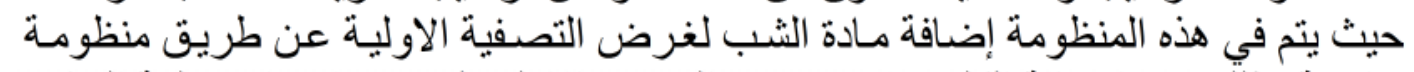

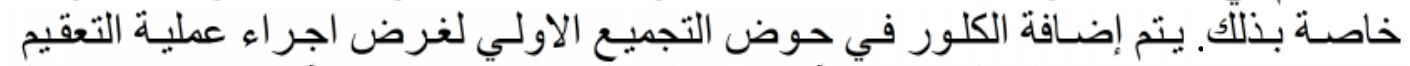

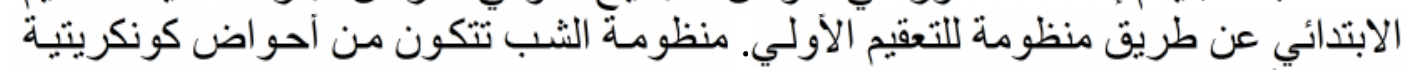

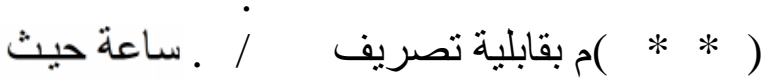

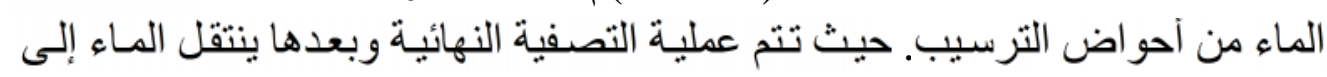

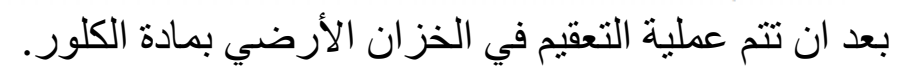

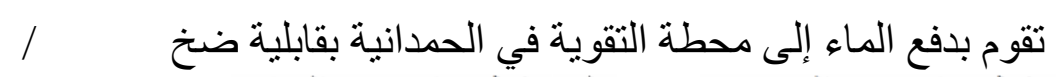

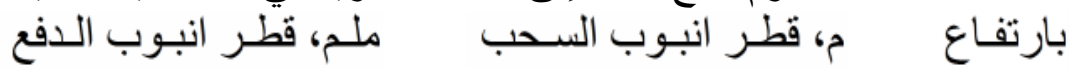

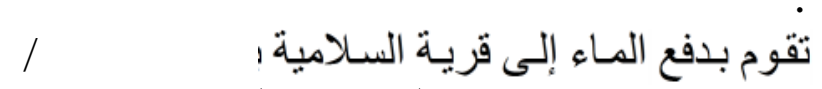
م إلى خزان السلامية.

• مضخات عدد تقوم بدفع المـاء إلى الخزان العـالي في قريـة كاني حر امي بقابلية ضـخ

المستخدمة في عملية غسل المرشحات بقابلية

/سـاعة للتعقيم النهائي وبسعة ) . ( )

ـمنظومة التعقيم: تتكون من اجهزة تعقيم عدد

. ( . * * )

/ساعة للتعقيم الابتدائي. 


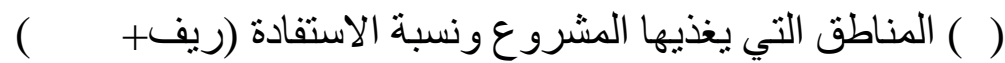

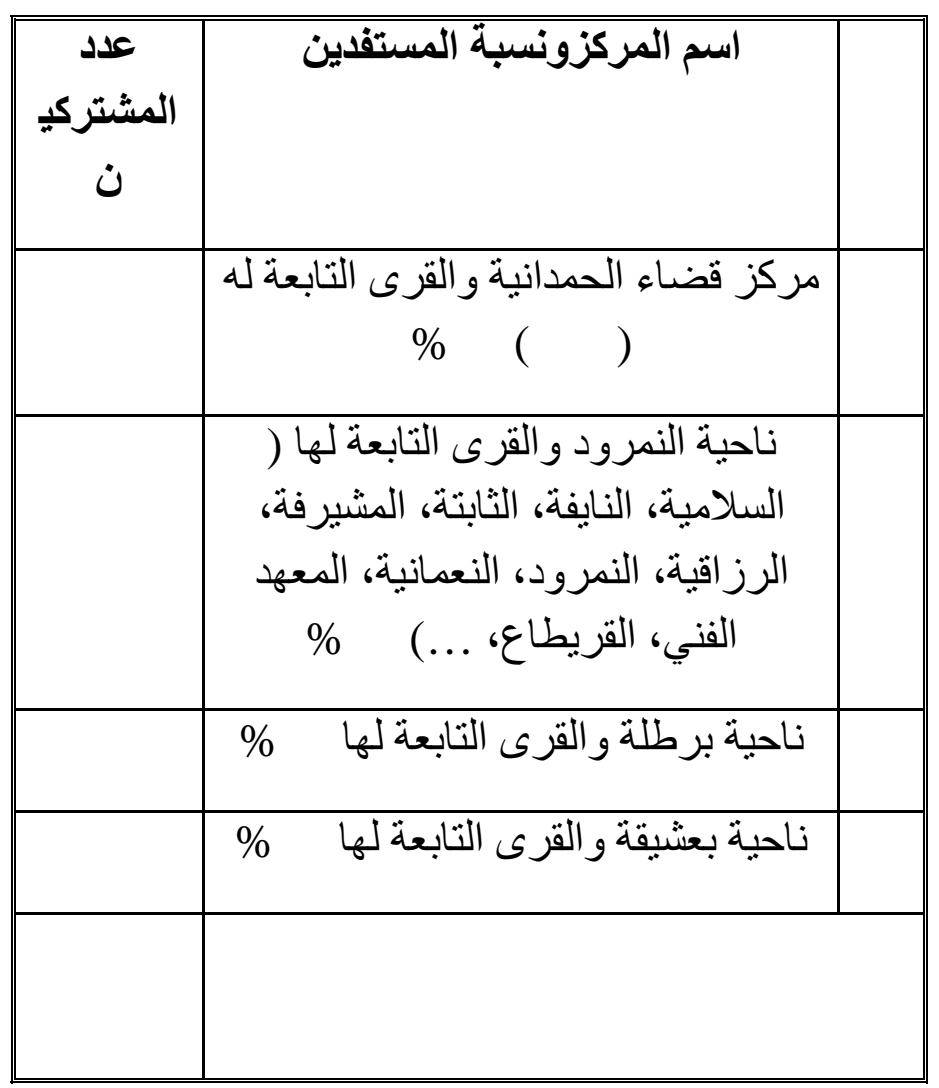

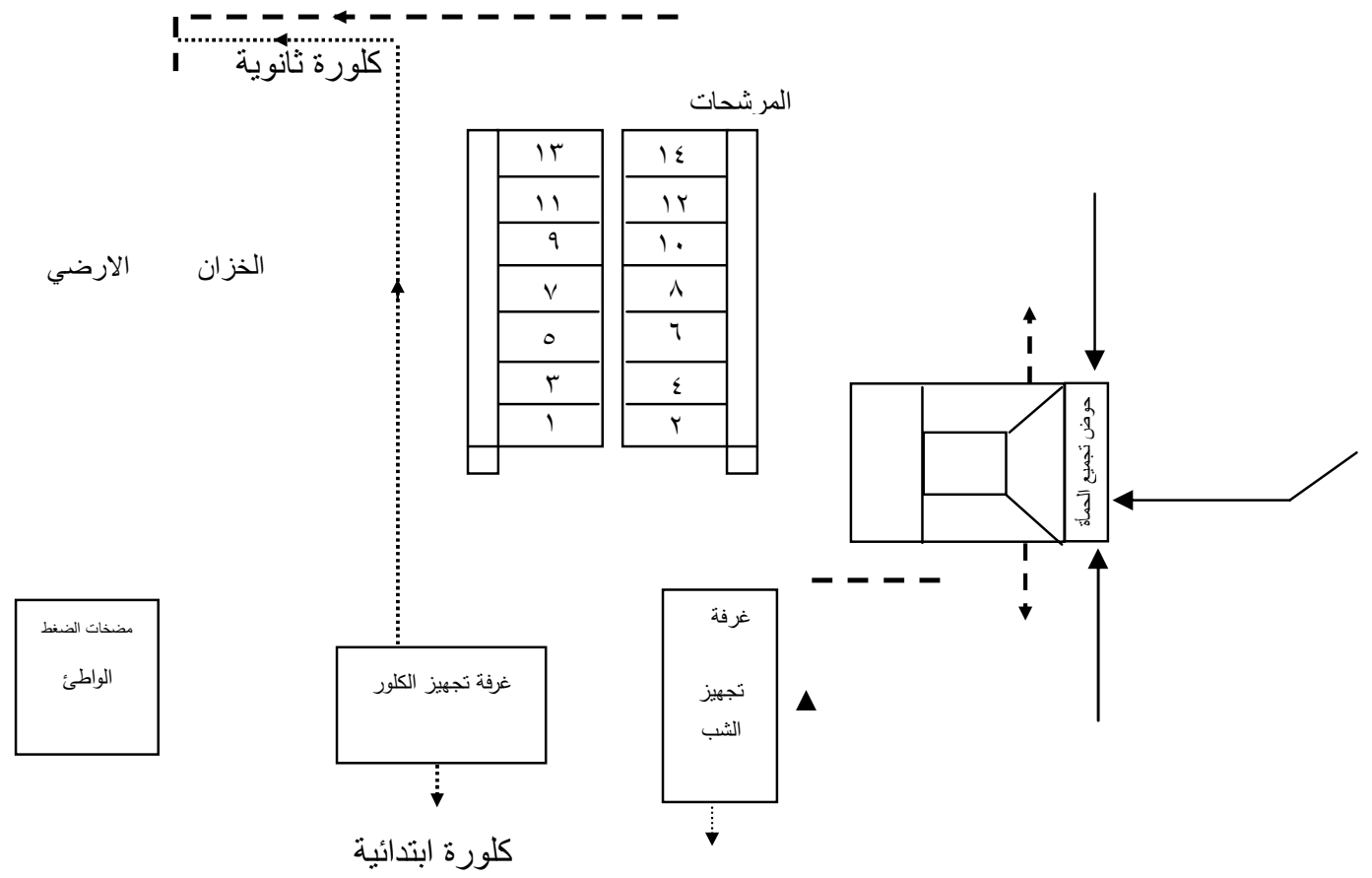




\begin{tabular}{llll} 
Al-Rafidain Engineering & Vol.15 & No.2 & 2007 \\
\hline
\end{tabular}

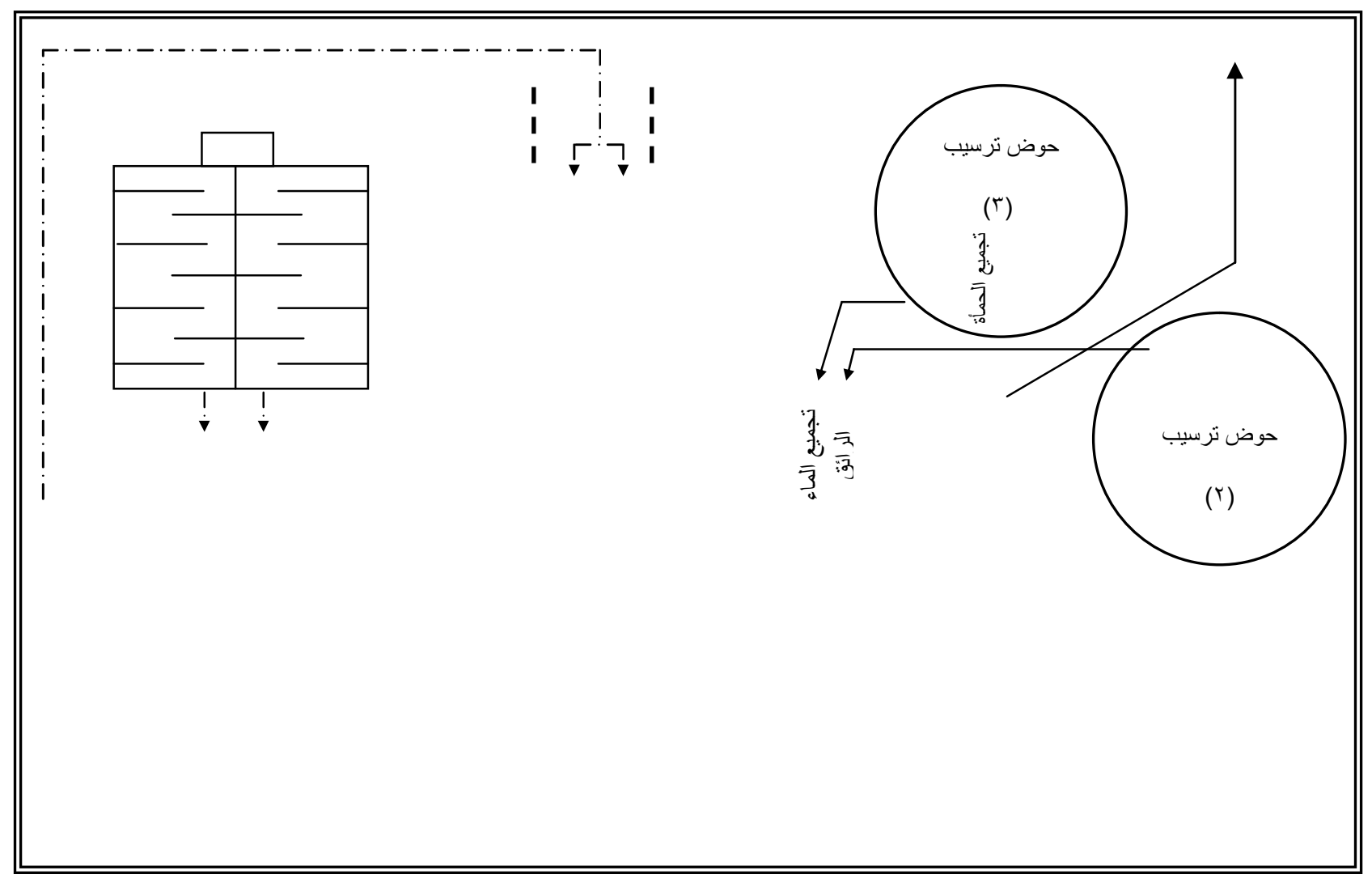

مخطط عام يوضح محطة السلامية

طريقة العمل
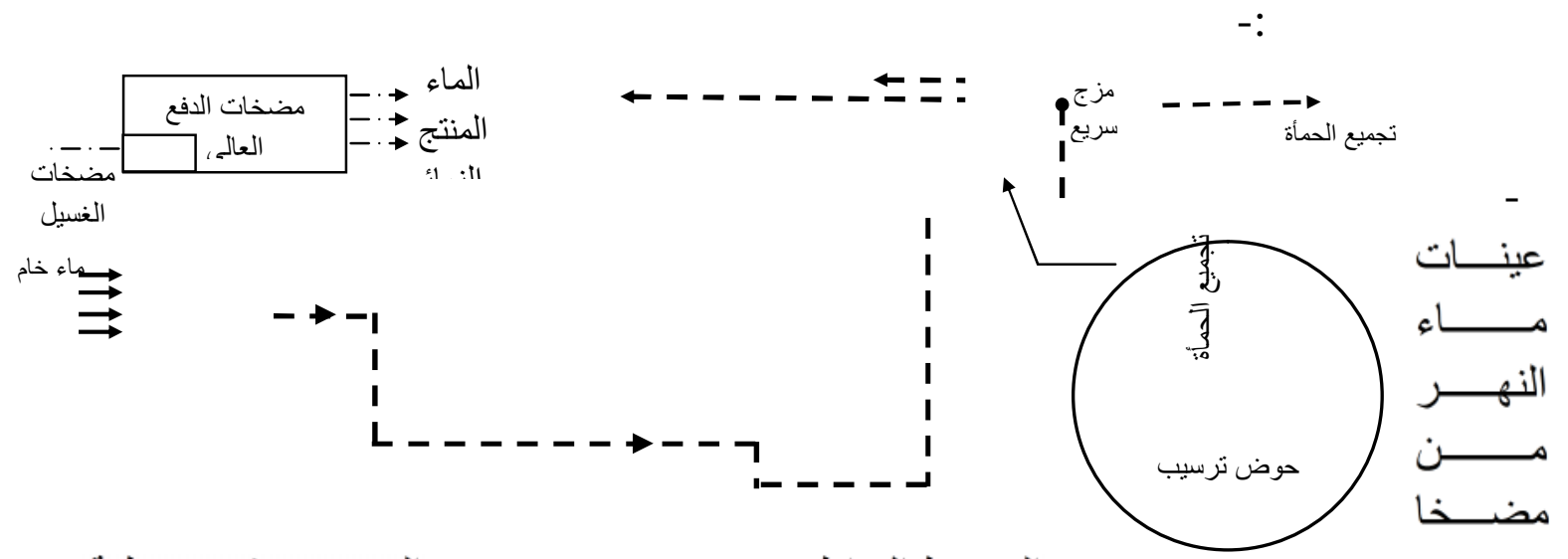

الضـغط الـواطى (low lift pump) الموجودة في محطـة 


$$
\text { - }
$$

نم اخذ نماذج الماء مرتين في كل اسبوع آي ثمانيـة نمـاذج شهريا ولمدة آثني عشر شهر السنة

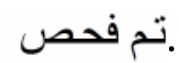

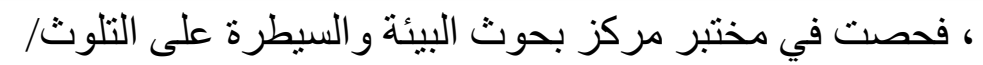

$$
\text { - قياس درجة الحرارة باستخدام محرار. }
$$

ـ التوصيل الكهربائي باستخدام جهاز Electrical conductivity meter.

ـالكدرة باستخدام جهاز Turbidity model 2100A.

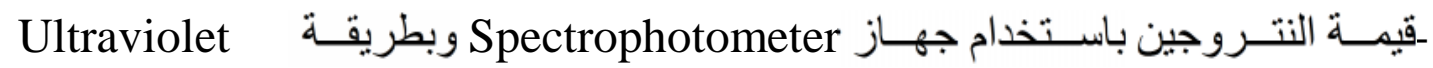
.Spectrophometric Screening Spectrophotometer باستخدام جهاز $\left(\mathrm{PO}_{4}\right)$

ـ العسرة الكلية باستخدام طريقة EDTA titration.

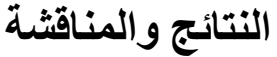

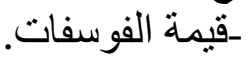

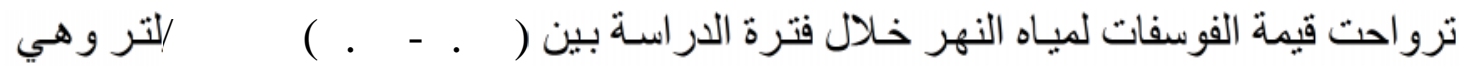

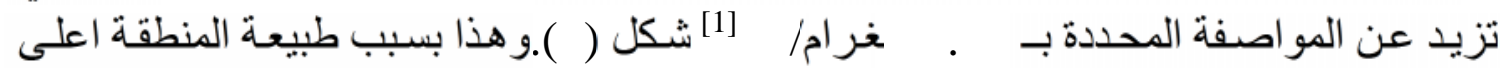

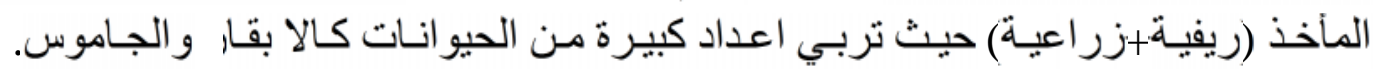

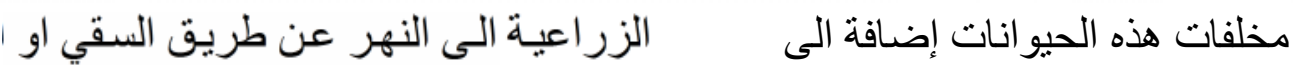

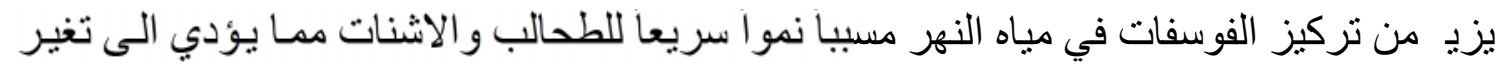
في نو عبة ماء النهر و انسداد المأخذ بشكل مستمر. ـ قيمة النتروجين. 
|

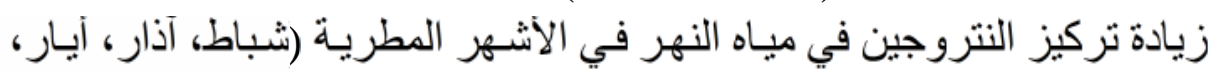

تشرين الأول، تشرين الثاني، كانون الاول)

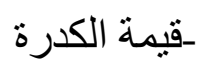

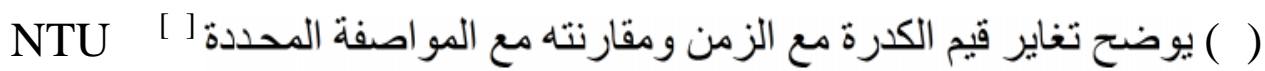

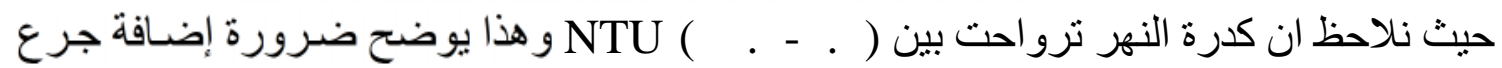

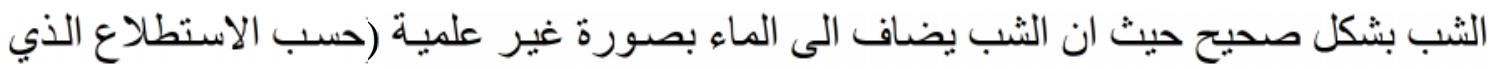

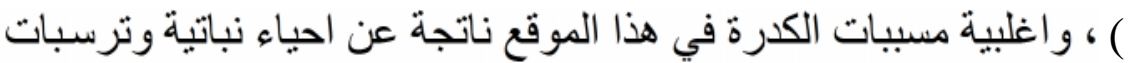

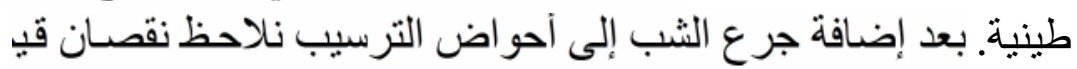

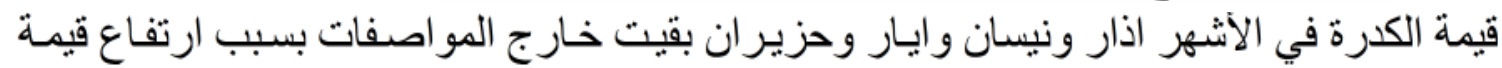

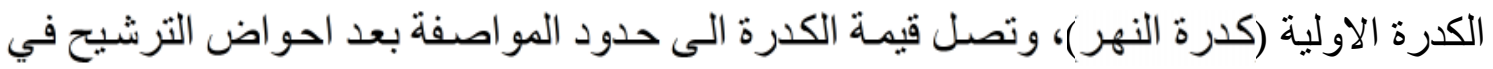

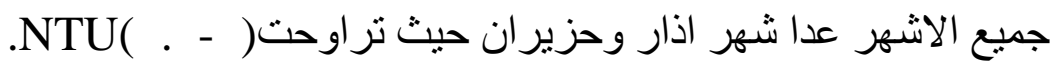

T-test

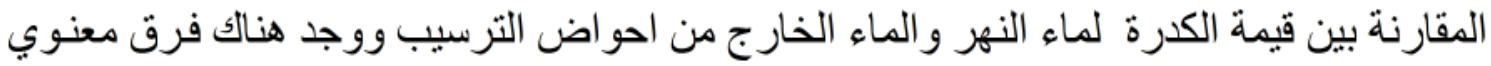

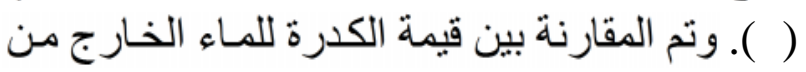

P $₫ 0.05$

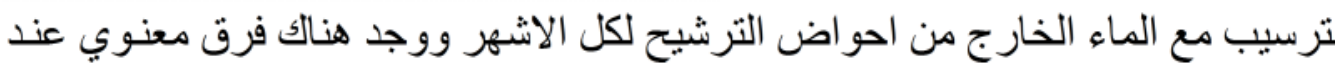

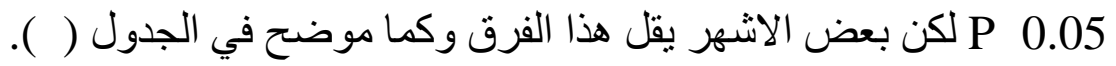

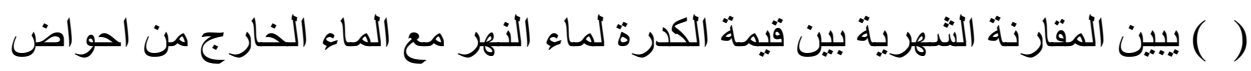

T-test الترسيب باستخدام التحليل الاحصني

\begin{tabular}{|c|c|c|c|c|}
\hline \multicolumn{2}{|l|}{$\%$} & \multirow{2}{*}{ المعياري } & & \multirow[t]{2}{*}{ الثهر } \\
\hline القيمة الاعلى & القيمةالو اطنئة & & & \\
\hline$\cdot$ & $\cdot$ & . & $*$ & \\
\hline . & . & . & * & \\
\hline . & . & . & *. & \\
\hline . & . & . & * & نيسان \\
\hline . & . & . & * & ايار \\
\hline . & 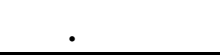 & . & $*$ & حزيران \\
\hline$\cdot$ & $\cdot$ & . & * & \\
\hline . & . & . & * & \\
\hline . & . & . & $*$ & ايلول \\
\hline . & - & - & $*$ & تشرين \\
\hline 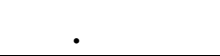 & . & . & * & تشرين \\
\hline
\end{tabular}


No.2

\begin{tabular}{|l|l|l|l|l|l|}
\hline & & & & & \\
\hline$\cdot$ & $\cdot$ & $\cdot$ & $\cdot$ & $* \cdot$ & \\
\hline
\end{tabular}


No. 2

2007

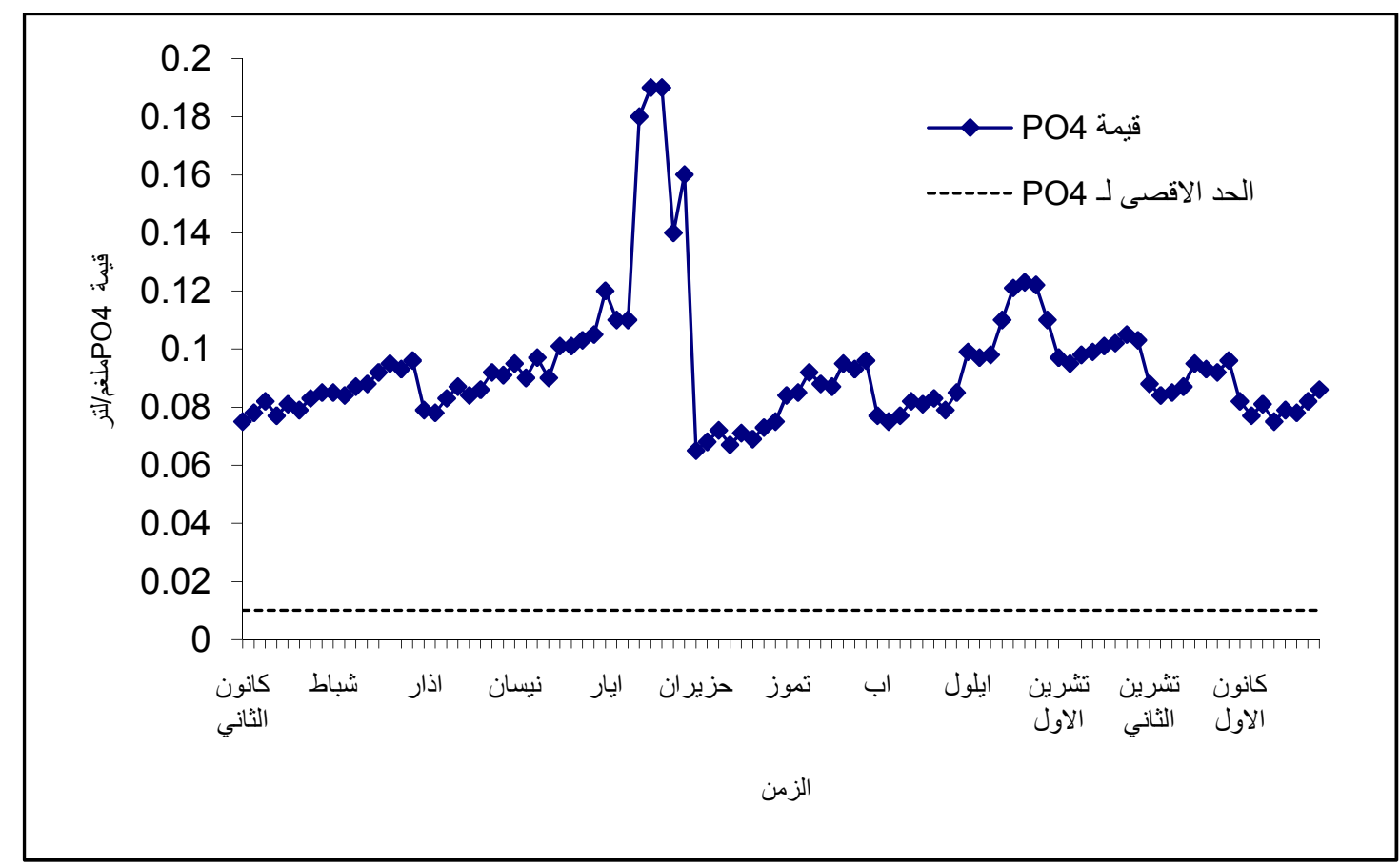

شكل رقم (1) تغاير قيمة PO4 مع الزمن عند مأخذ محطة

$$
\text { السلامية }
$$

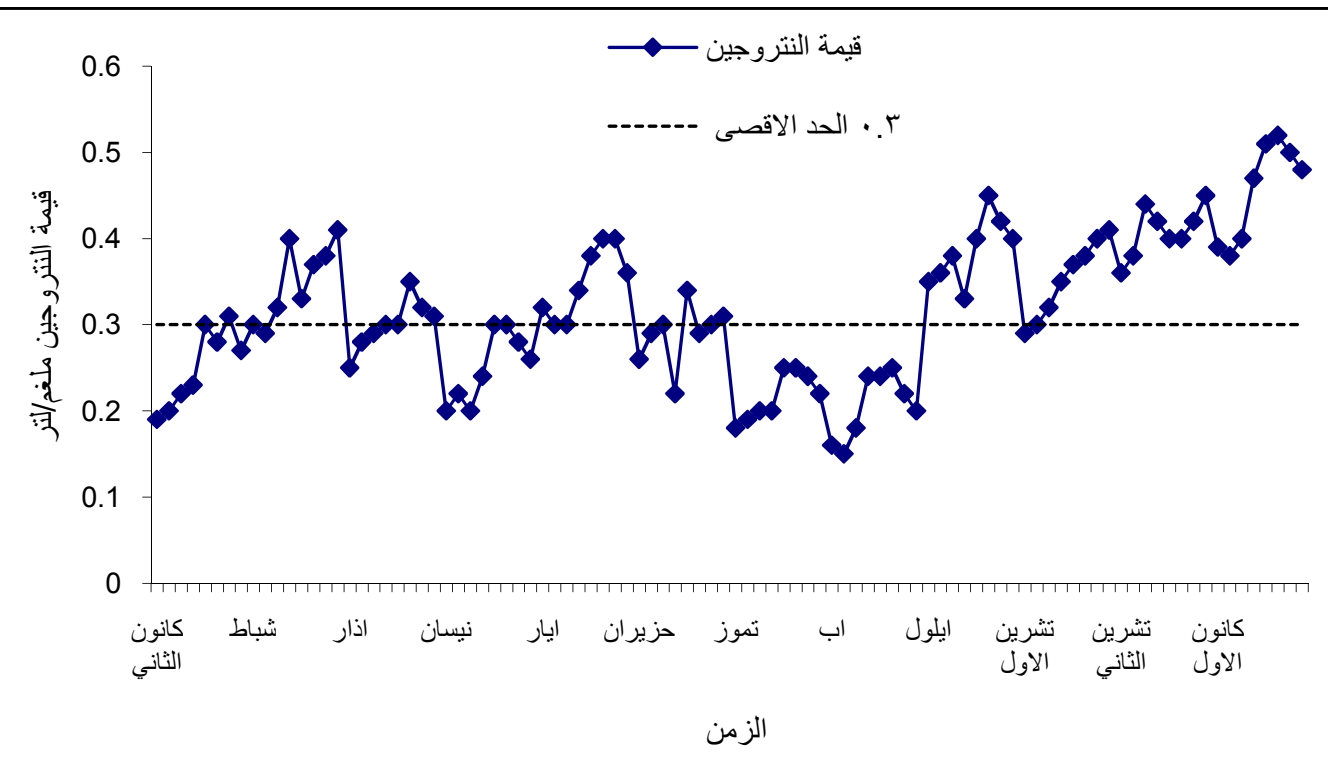




\begin{tabular}{llll} 
Al-Rafidain Engineering & Vol.15 & No.2 & 2007 \\
\hline
\end{tabular}

$$
\text { شكل رقم (Y) تغاير قيمة النتروجين مع الزمن عند مأخذ }
$$

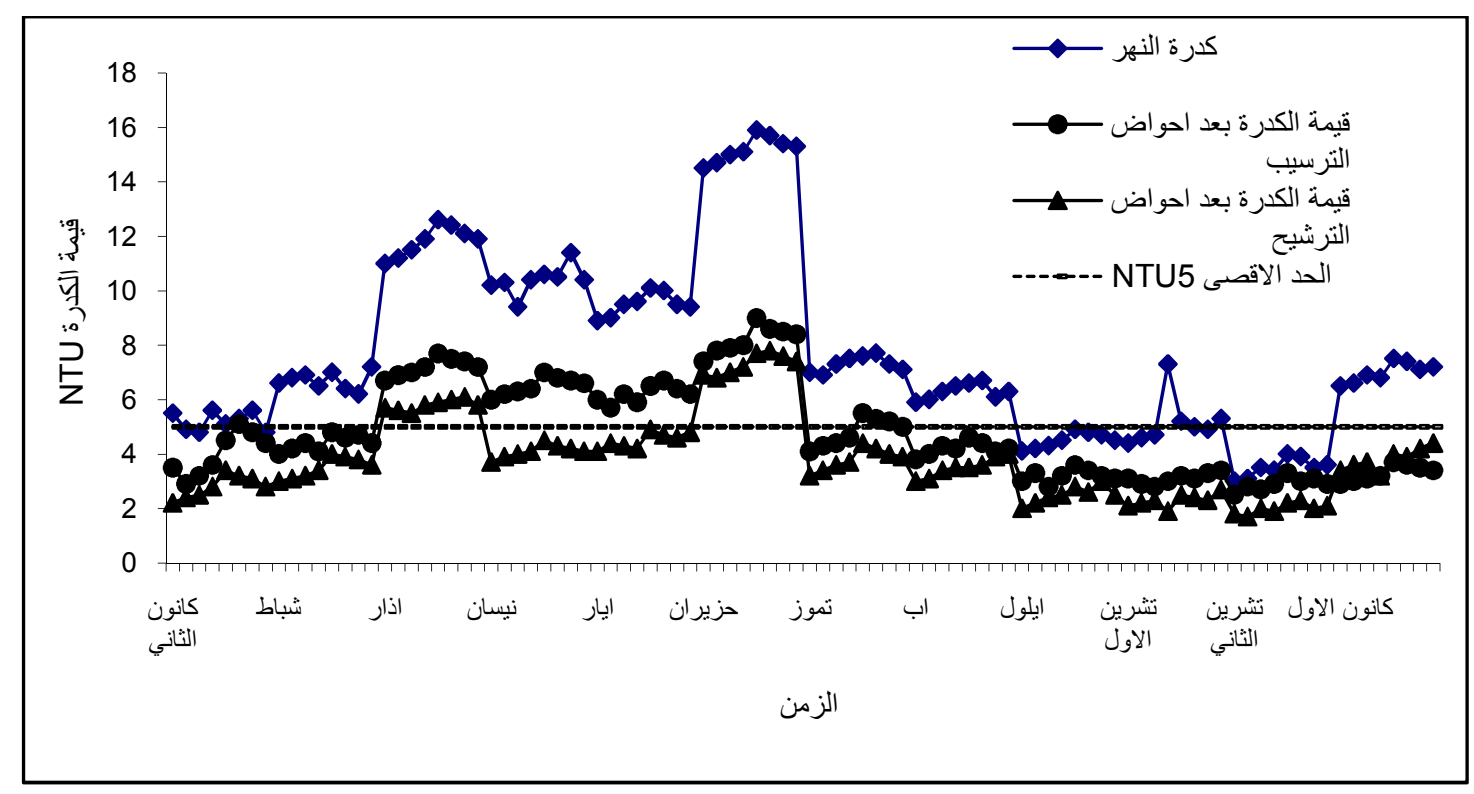

شكل رقم (3) تغاير قيمة الكدرة في النهر وفي وحدات المحطة 


\begin{tabular}{llll} 
Al-Rafidain Engineering & Vol.15 & No.2 & 2007 \\
\hline
\end{tabular}

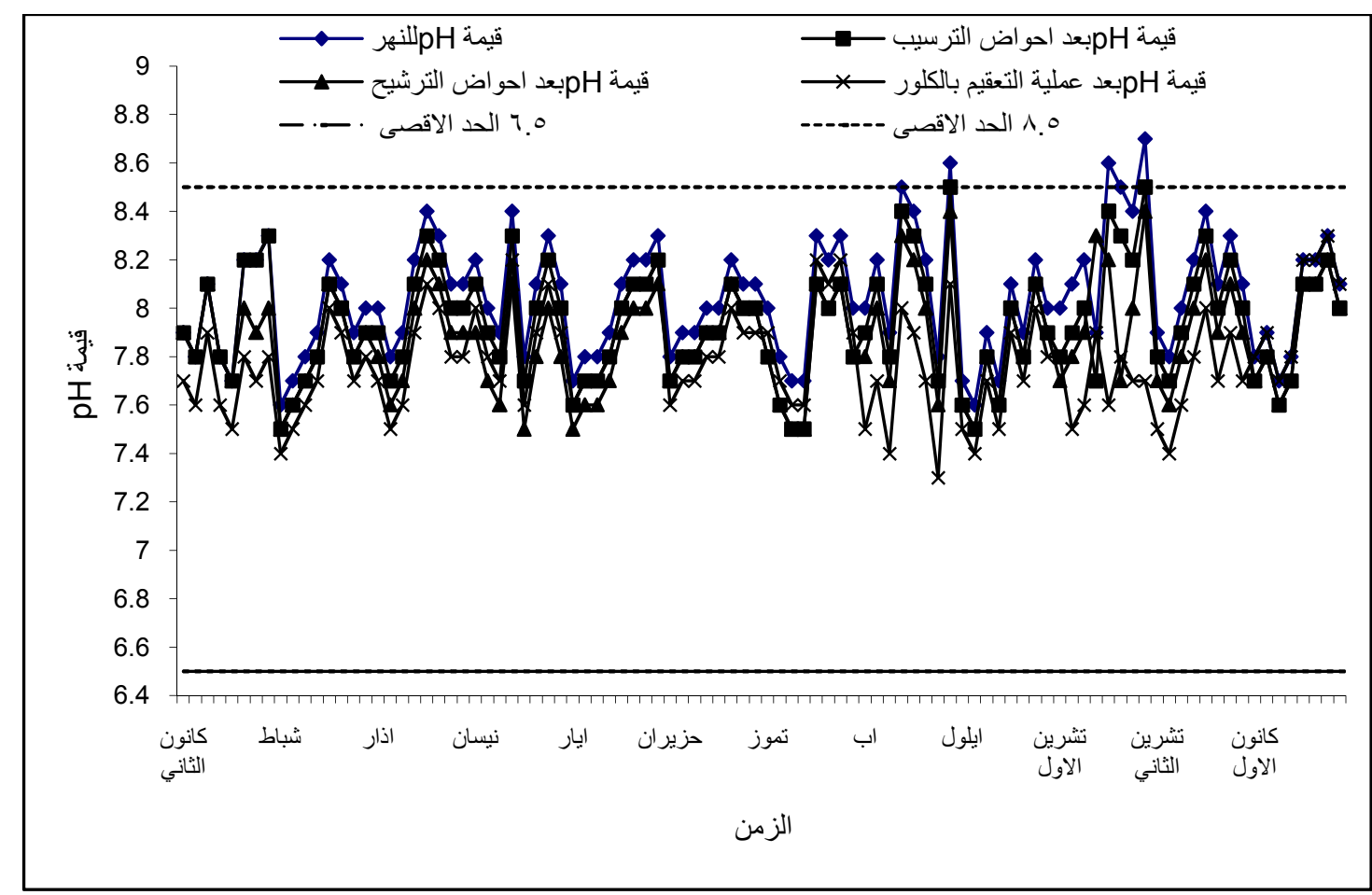

شكل رقم (ع ) تغاير قيمة pH في النهر وفي وحدات المحطة 
(3) يبين المقارنة الثهرية بين قيمة الكدرة لماء الخارج من احو اض الترسيب مع الماء

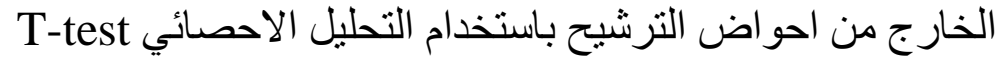

\begin{tabular}{|c|c|c|c|c|c|}
\hline \multicolumn{2}{|l|}{$\%$} & & \multirow{2}{*}{ المعياري } & & \multirow[t]{2}{*}{ الثهر } \\
\hline يمة الاعلى & القيمةالو اطنئة & & & & \\
\hline$\cdot$ & & • & $\cdot$ & $*$ & \\
\hline . & & . & . & $*$ & \\
\hline . & & . & . & $*$ & \\
\hline . & . & . & . & $*$ & نيسان \\
\hline . & . & . & . & $*$ & ايار \\
\hline . & . & . & . & $*$ & حزيران \\
\hline . & . & & . & . & \\
\hline . & & . & . & & \\
\hline . & . & . & . & $*$ & ايلول \\
\hline$\cdot$ & & $\cdot$ & . & $*$ & تشرين \\
\hline 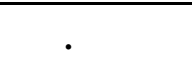 & & $\cdot$ & & $*$ & تشرين \\
\hline & & • & & & \\
\hline & & & & & \\
\hline
\end{tabular}

$\mathrm{P} \unlhd 0.05 \quad *$

( ) يبين الاز الة بعد احواض الترسيب وبعد احواض الترشيح للعكورة خـلال اثـهر

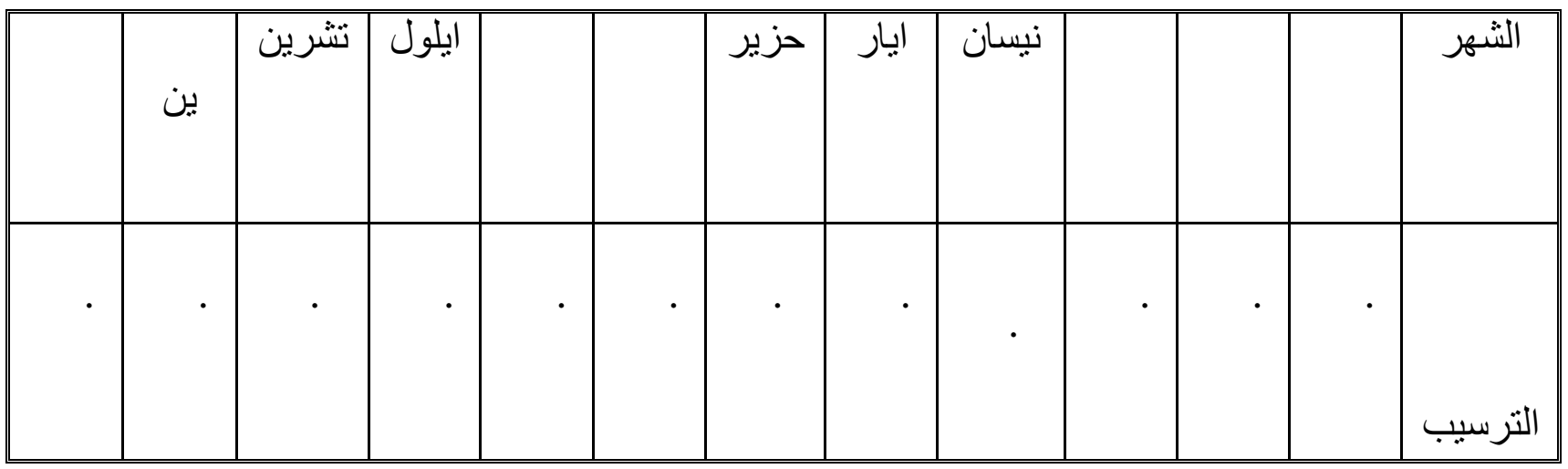




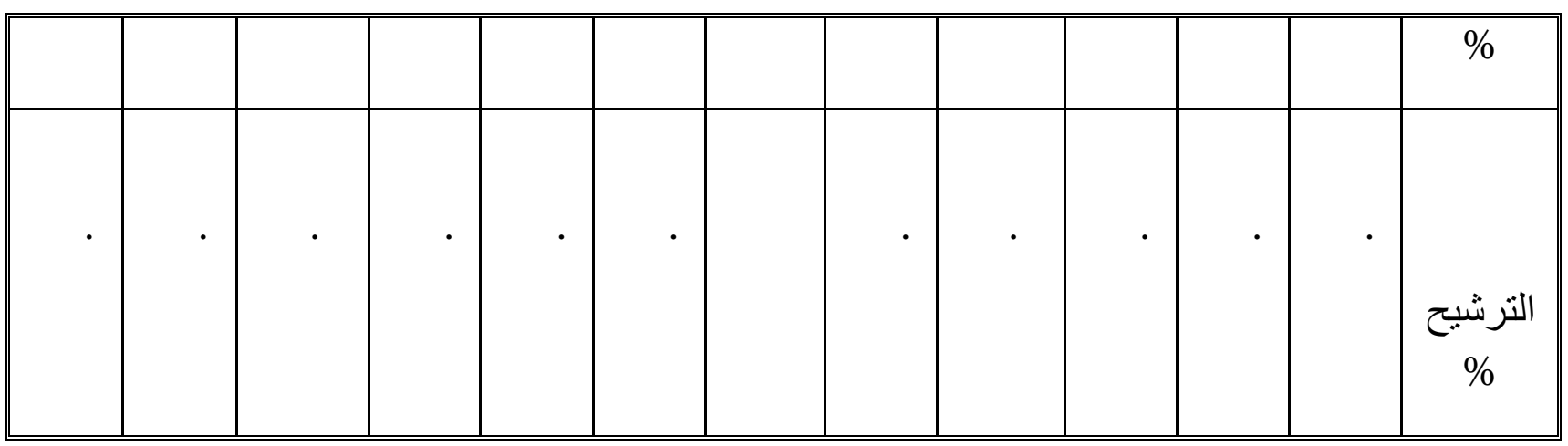

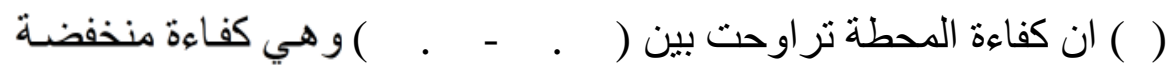

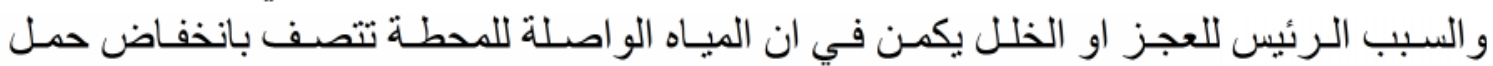

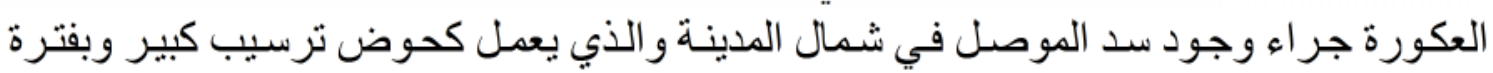

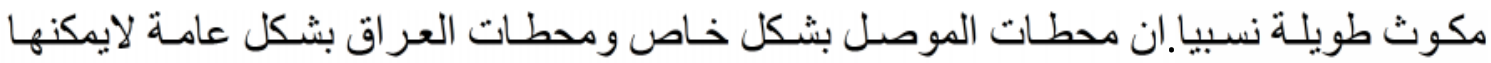

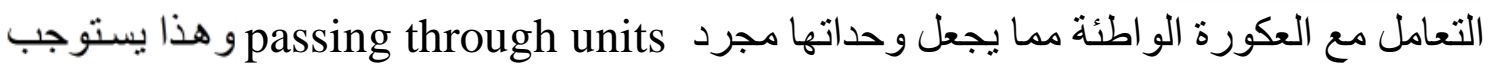
استخدام تقنيات غير تقلبية يمكنها التعامل مع ظروف العية العكورة الواطئة.

$$
\text { pHتقيمة }
$$

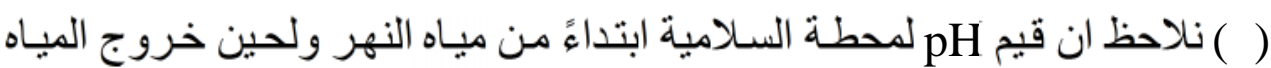

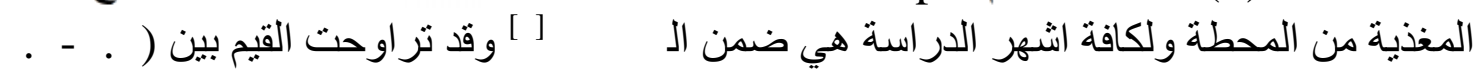

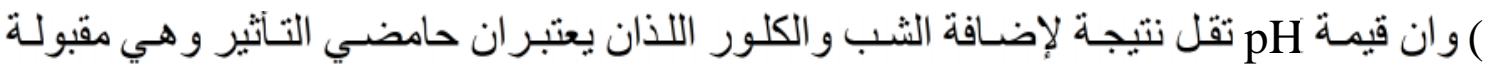

\section{EC قبمة}

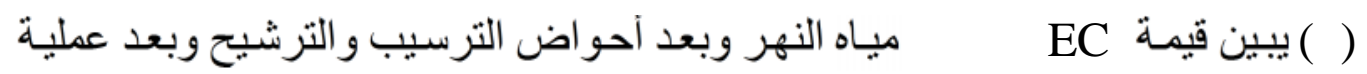

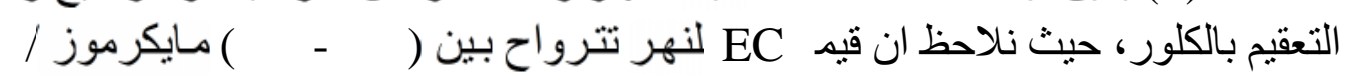

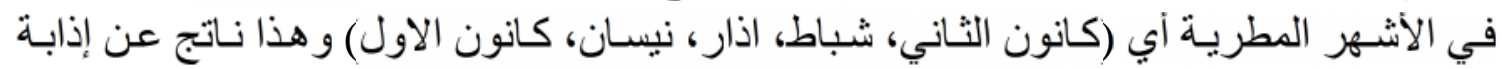

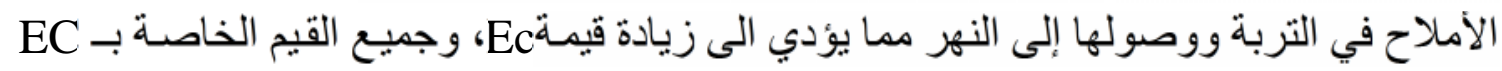

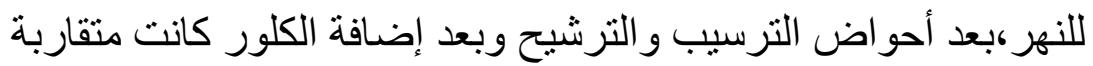

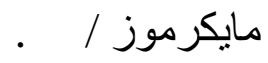

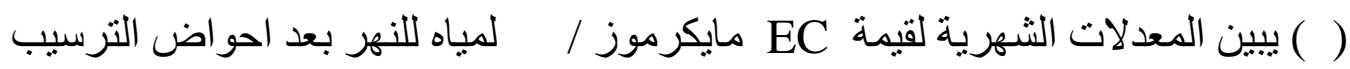
6بعد احو اض الترشيح وبعد التعقيم 
No.2

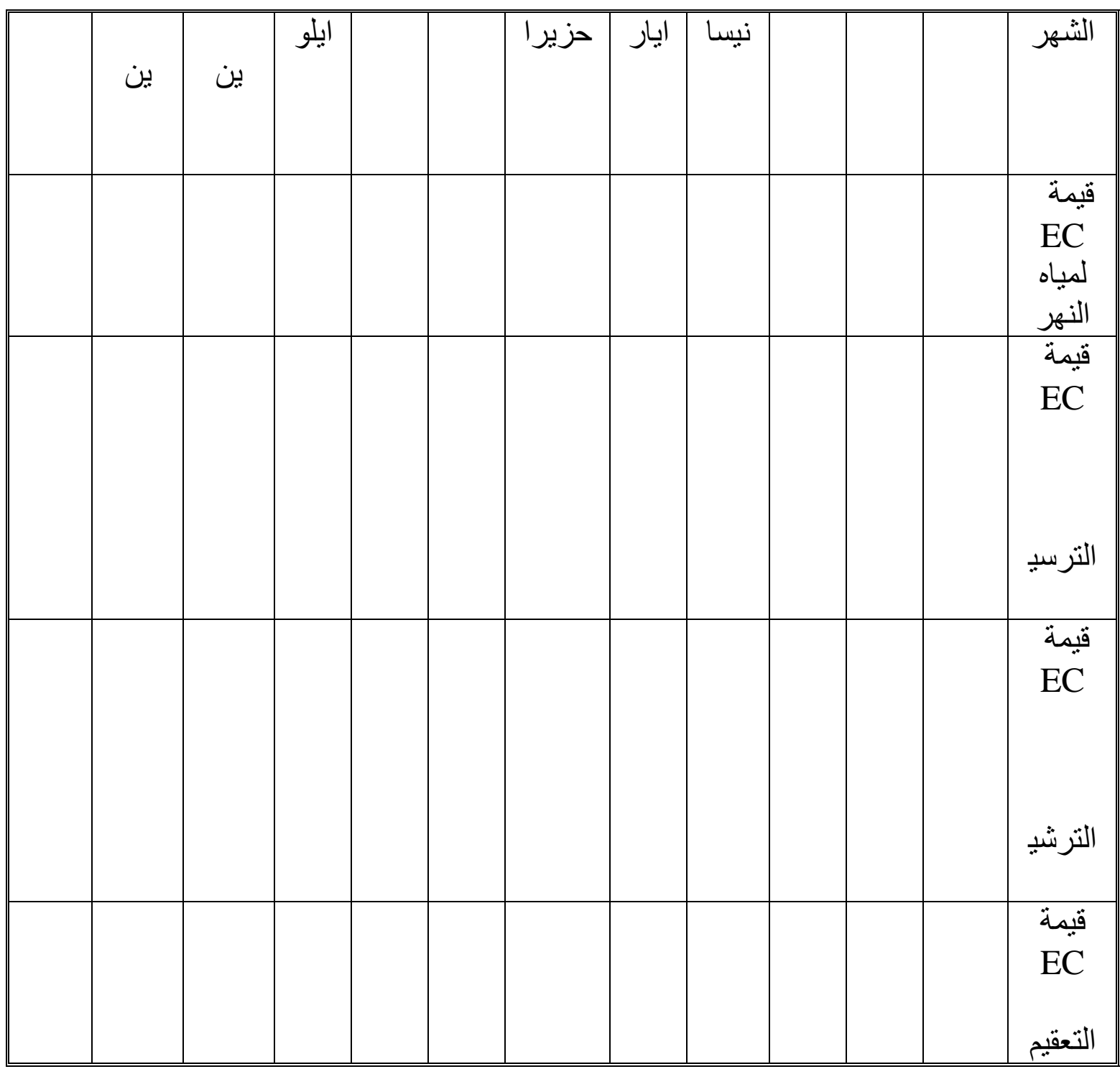

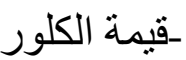

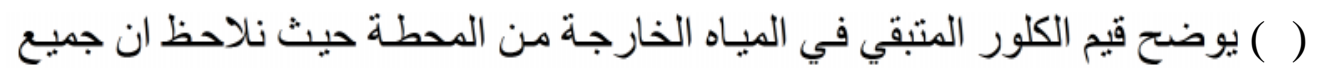

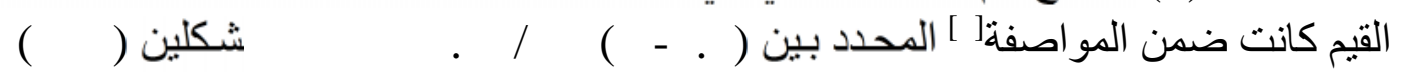

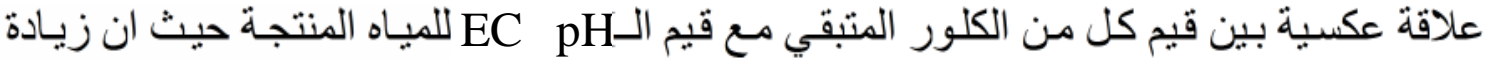

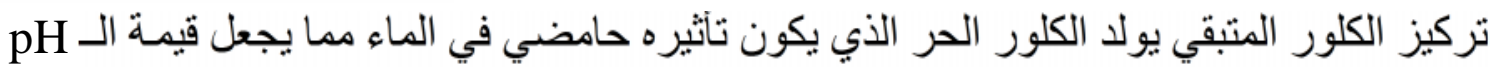




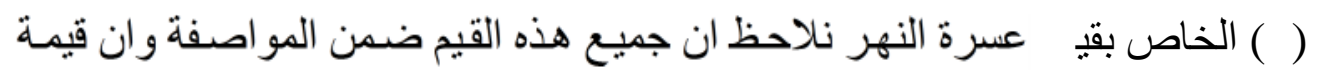

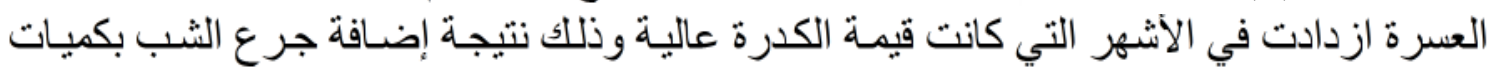

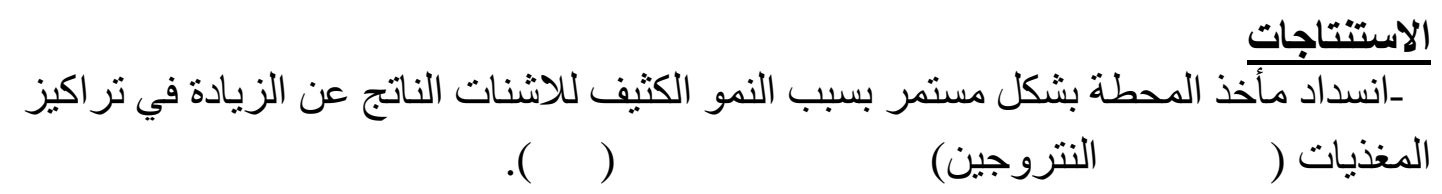
- زيادة قيم EC بشكل واضح في الأشهر المطرية وهذا ناتج عن اذابة الاملاح الموجوده في ـ كفاءة عمل المحطة تراوحت بين ( و هذا يذل على وجود مشاكل في عمل و لايمكنها 


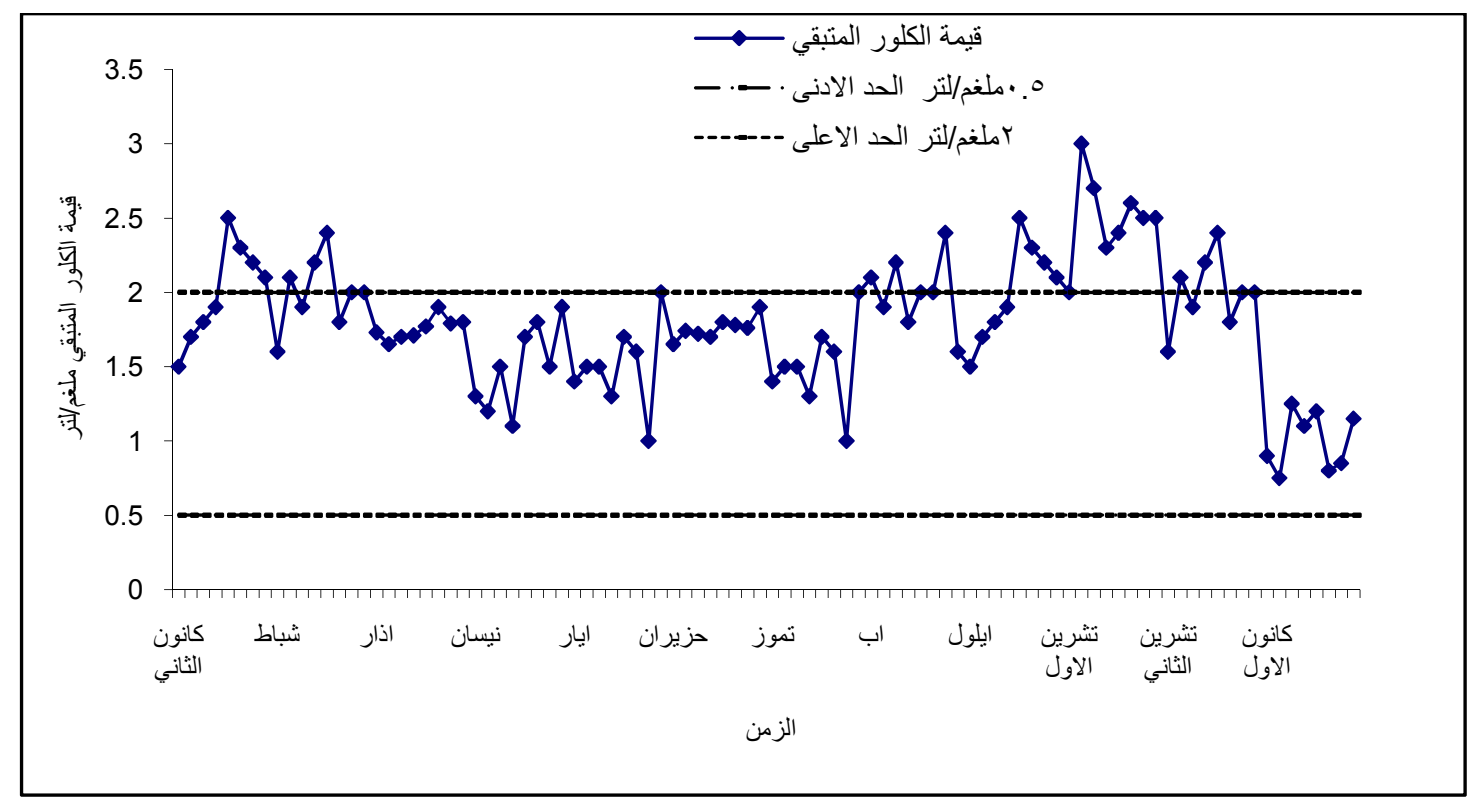

شكل رقم (0) قيم الكلور المتبقي مع الزمن في مياه الدفع 


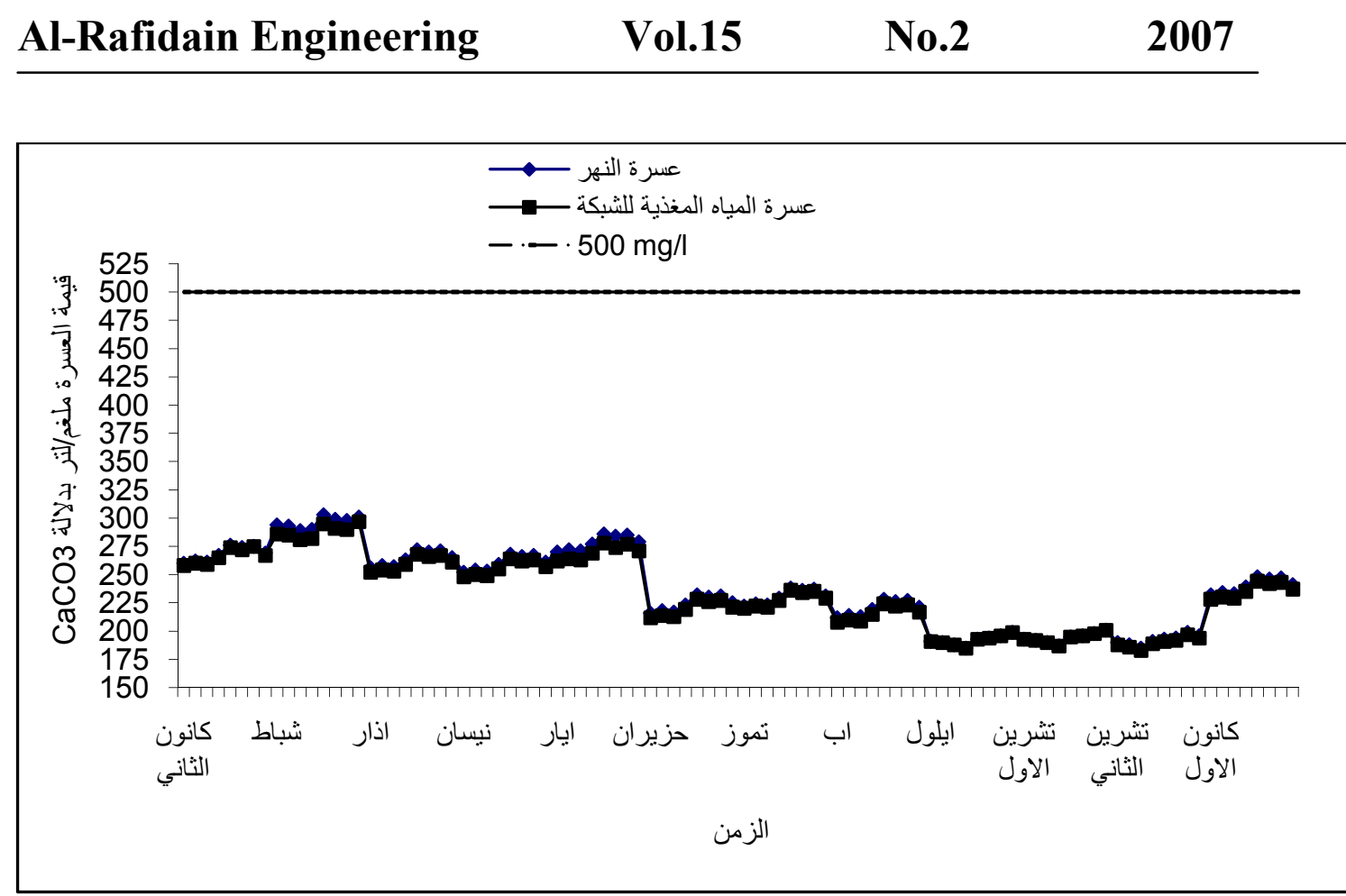

شكل رقم (آ) يوضح قيم العسرة مع الزمن ولكل من النهر وعسرة المياه الخارجة من المحطة 


\begin{tabular}{llll} 
Al-Rafidain Engineering & Vol.15 & No.2 & 2007 \\
\hline
\end{tabular}

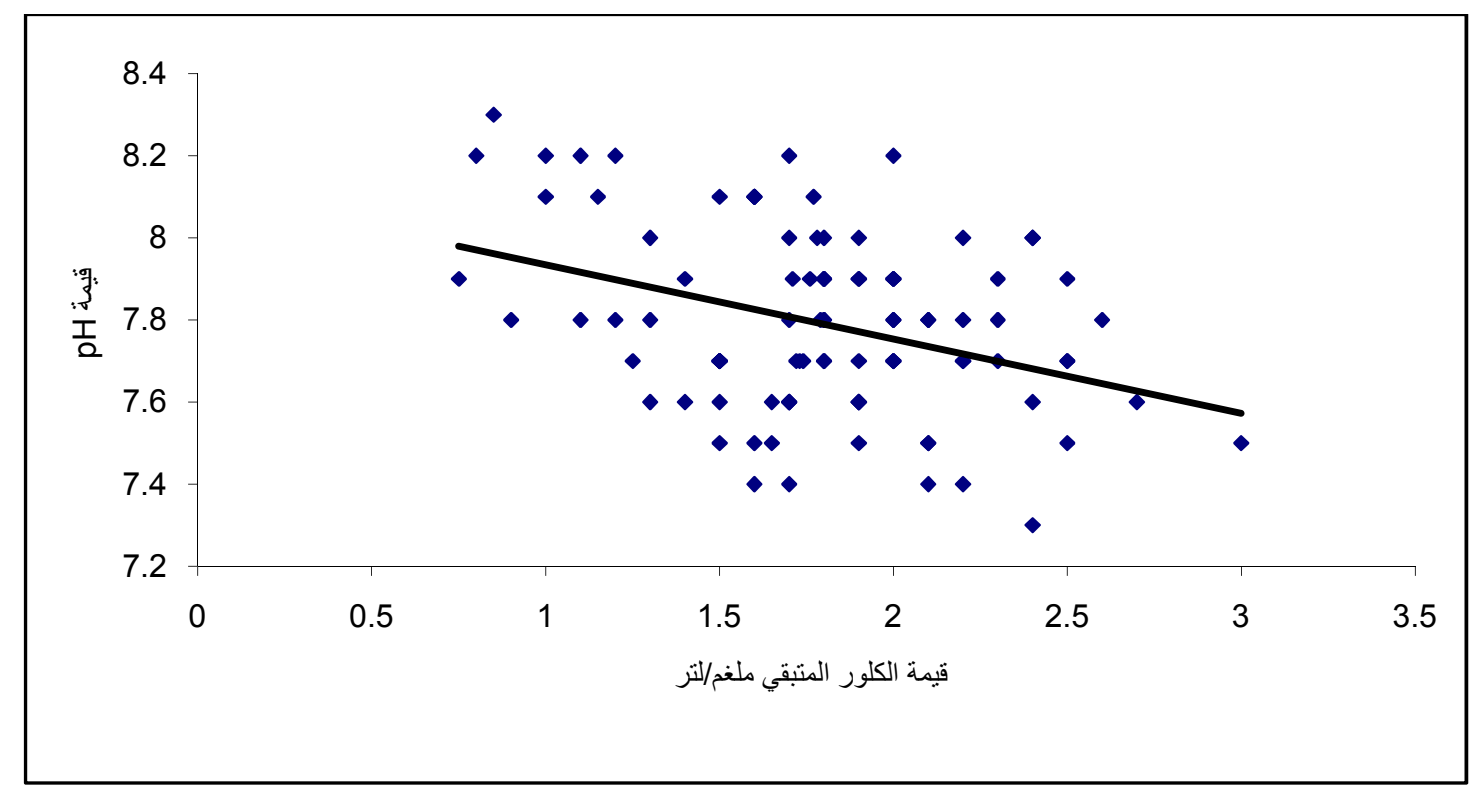

شكل رقم (V) يوضح طبيعة العلاقة بين قيمة الكلور

pH وقيمة

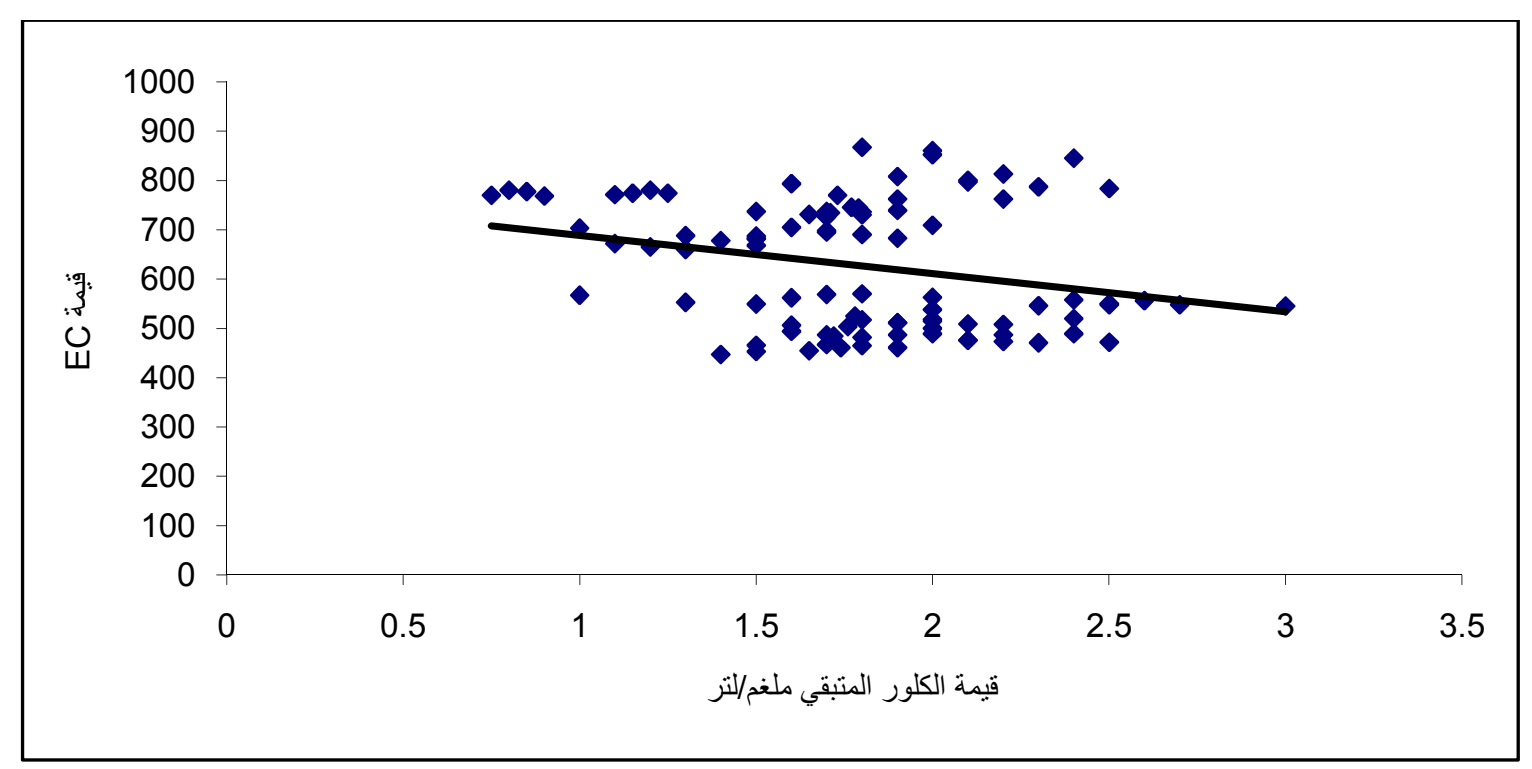

شكل رقم (^) يوضح طبيعة العلاقة بين قيمة الكلور وقيمة EC 


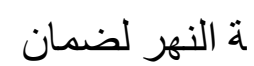

-تغيير موقع انابيب السحب حيث يتم ابعاد نو عية افضل ولتقليل من مشاكل انسداد الماخذ.

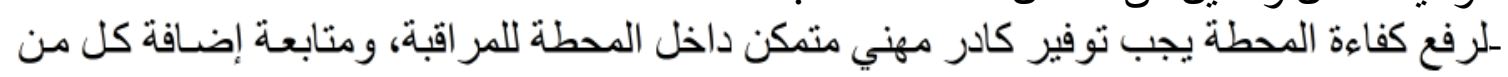
جر عة الثب و الكلور وفترة بقاء الماء في كل من أحو اض الترسيب و الترشيح.

$\underline{\underline{J}}$

المصادر العربية

سعاد عبد وحسن، محمد سليمان "الهندسة العملية للبيئة فحوصات الماء"

المصادر الاجنبية

2- Rosen, B. and Morling S., "A systematic approach to optiomal upgrading of water and wastewater treatment plants", J. Wat. Sci. Tech., Vol.37, No.9, 1998.

3- Buckey, C.B., " Potato water cost: effective treatment and control”, J. Inst. Water Eng. Sci., Vol.38, No.3, 1984.

4 Peirce, J.J., Weiner, R.F. and Vesilind, P.A., "Environmental pollution and control", $4^{\text {Th }}$ edition , Butterworth-Heinemann,USA.,1998.

5- WHO, World Health Organization, "Guidelines for Drinking water Quality, Recommendations”, Vol.1, Geneva, 1984.

6- Sawyer, C.N. and McCarty,P.L, "Chemistry for environmental engineering", $3^{\text {rd }}$ edition, McGraw Hill Co,1978.

7- Train, R.E., "Quality criteria for water" U.S Environmental Agency, Washington D.C., Castlehe House publication Ltd 1979. 
8- WHO, World Health Organization "Guideline for Drinking water Quality, Recommendation” 1998.

9-Hudson Jr. H.E, "Evaluation of plant operating and jar test datd", JAWWA, Vol.65, No.5, 1973.

10- Joyce, M., "Does drinking water hardness affect cardiovascular disease", Journal of Environmental Health, Vol.43, NO.3, 1980. 
